\title{
Evaluation of antiurolithiatic effects of Parmelia perlata against calcium oxalate calculi in hyperoxaluric rats
}

\author{
Parveen Kumar Goyal ${ }^{1,2}$, Santosh Kumar Verma ${ }^{3}$, Anil Kumar Sharma ${ }^{4 *}$ \\ 'Research Scholar, I.K.G. Punjab Technical University, Kapurthala (Punjab), India. \\ ${ }^{2}$ Department of Pharmacology, Hindu College of Pharmacy, Sonepat (Haryana), India. \\ ${ }^{3}$ Faculty of Pharmaceutical Sciences, Motherhood University, Roorkee (Uttrakhand), India. \\ ${ }^{4}$ Department of Pharmaceutical Sciences, CT institute of Pharmaceutical Sciences, Jalandhar (Punjab) India.
}

\section{ARTICLE INFO \\ Article history: \\ Received on: 12/09/2017 \\ Accepted on: 17/11/2017 \\ Available online: 28/01/2018}

Key words:

Parmelia perlata, Urolithiasis, Hyperoxaluria, Ethylene glycol, Oxalate calculi

\begin{abstract}
This manuscript was aimed to evaluate the antiurolithiatic potential of Parmelia perlata extract (PPE) against calcium oxalate calculi in experimental rats. The drinking water containing $0.75 \% \mathrm{v} / \mathrm{v}$ Ethylene Glycol (EG) and 1\% w/v Ammonium Chloride (AC) was used to induce hyperoxaluria in Wistar rats. Thirty-six rats divided into six groups (each containing six animals) were treated with vehicle (Normal control), EG + AC (Urolithiatic control), Cystone (Standard), and 100, 300 and $500 \mathrm{mg} / \mathrm{kg}$, PPE (Tests). Administration of EG + AC produced significant hyperoxaluria and altered biochemical parameters of urine, serum and kidney tissue homogenates in lithiatic group. It caused glomerular atrophy, tubular deposition of oxalate crystals, altered renal architecture and impaired renal functions. PPE (100, 300 and $500 \mathrm{mg} / \mathrm{kg}$, p.o., once daily for four weeks) significantly $(\mathrm{p}<0.05)$ reversed the biochemical changes in urine, serum, and kidney tissue homogenates. It restored the normal renal functions and biochemical parameters like urinary $\mathrm{pH}$, volume, creatinine clearance, BUN levels, uric acid concentrations and some inorganic parameters like oxalate, calcium, phosphorus contents, etc. The histopathological studies revealed that PPE restored the normal renal architecture in lithiatic rats. Conclusively, the experimental findings showed that PPE exhibited significant antiurolithiatic potential against calcium oxalate calculi in experimental rats.
\end{abstract}

\section{INTRODUCTION}

Urolithiasis or nephrolithiasis, presence of calculi in kidney or any part of urinary tract, is the third most prevalent renal disease that afflicting humankind since antiquity. It jeopardised the public health worldwide, sparing no geographical area. More than $80 \%$ of renal stones are composed of calcium oxalate $(\mathrm{CaOx})$ and occurs in two forms i.e. mono and di-hydrates of $\mathrm{CaOx}$ (Aggarwal et al., 2013; Goyal et al., 2017; Khan, 1997). Urinary stone formation occurs as a result of cascade of physiochemical events started with supersaturation of urine and followed by nucleation, growth, aggregation and retention of crystals (Li et al., 2017; Moe, 2006). Despite of recognition of urolithiasis since stone-age and tremendous advances in the field of urology, in modern system of med-

"Corresponding Author

Anil Kumar Sharma, Department of Pharmaceutical Sciences, CT institute of Pharmaceutical Sciences, Jalandhar-144020, Punjab, India.E-mail:aksharma91@gmail.com icines, except few alkalizers and diuretics, there is no clinically satisfactory medicine that can either dissolve and/or prevent the formation or recurrence of urinary stones (Goyal et al., 2017). It is usually treated by some surgical and interventional techniques like Percutaneous Nephrolithotomy, Ureteroscopy, Extracorporeal Shock Wave Lithotripsy, etc. Such techniques cannot hamper, even facilitate, the chances of stone recurrence and have some serious side effects like haemorrhage, renal fibrosis, infections, etc. (Li et al., 2017). Therefore, after adopting these treatment procedures, the patients have to be subjected to careful follow up for long time, and moreover these procedures are prohibitively costly for a common man. So there is a constant need to identify some more clinically useful antiurolithiatic therapies that alter the rate of recurrences, have minimum or no side effects, and affordable for a common man.

In alternative systems of medicines, many herbal remedies are available for urolithiasis which are quite efficacious and have comparatively lesser side effects. There are many herbal drugs which are traditionally prescribed for renal calculi, and even 
used as the ingredient in some composite herbal formulations prescribed for urolithiasis patients, but, rationale behind their use has not been scientifically substantiated using modern methodology.

One such herbal lichen Parmelia perlata was identified and focussed in this manuscript. P. perlata (Huds.) Ach., belonging to family Parmeliaceae, is commonly known as Chharila, Some other common names like Stone flower, Pattharphool, etc., given to this are probably because of its traditional therapeutic uses in urinary calculi (Goyal et al., 2016). It contains several phytoconstituents including lichen acids like lecanoric acid, atranorin, usnic acid (Khare, 2007; The Ayurvedic Pharmacopoeia of India, 2001), dibenzofuran (Sharma et al., 2014), terpenes (Abdullah et al., 2007), phenolic compounds, etc. (Sharma et al., 2012).

$P$. perlata has traditionally been recommended in sevaral renal diseases like urinary obstruction, calculi, dysuria, burning sensation, etc, and seminal weakness, spermatorrhoea, nocturnal emission, inflammations, general pains, etc. (Khare, 2007; Nadkarni, 2002; The Ayurvedic Pharmacopoeia of India, 2001). It is also used as the ingredient of some herbal composite formulations like Calcury (Charak Pharma Pvt. Ltd.), Pathrina (Shri Baidyanath Ayurved Bhawan Pvt. Ltd.), and Neeri (Aimil Pharmaceuticals, India Ltd.) prescribed for urolithiasis and improving renal functions (Goyal et al., 2016). It has been scientifically substantiated for antiulcer (Lakshmi et al., 2013), hepatoprotective (Shailajan et al., 2014), antidiabetic (Jothi and Brindha, 2013), antioxidant, hypolipidemic (Rahman et al., 2014), antimicrobial (Thippeswamy et al., 2013; Vidyalakshmi and Kruthika, 2012) effects, etc. There is no scientific report for its antiurolithiatic effects. The present manuscript is focussed to evaluate the hydroethanolic extract of $P$. paelata for antiurolithiatic potential against $\mathrm{CaOx}$ calculi in experimental rats.

\section{MATERIALS AND METHODS}

\section{Plant material}

The dried whole plant of Parmelia perlata (Huds.) Ach., (Family: Parmeliaceae), authenticated by the botanist Dr. H. B. Singh (Former Chief Scientist, Raw Materials Herbarium, and Museum, NISCAIR, New Delhi) was obtained as a gift sample from Aimil Pharmaceutical India Limited, New Delhi (Ref. No. AIMIL/PD/2015). A voucher specimen was deposited in the Department of Pharmacognosy, Hindu College of Pharmacy, Sonepat.

\section{Chemicals and reagents}

Ethylene glycol was purchased from Loba Chemie, Mumbai, India. Ammonium chloride was purchased from Thermo Fisher Scientific India Pvt Ltd. Mumbai, India. All diagnostic kits used for estimating the biochemical parameters were obtained from ERBA Diagnostic Mannheim GmbH, Germany. The reference herbal formulation Cystone (hereinafter designated as CST) was purchased from Himalaya Drug Company, Mumbai, India. All other chemicals and reagents used were of the at least analytical grade.

\section{Experimental animals}

Healthy adult Wistar rats, weighing 150-250 g and equivalent age (4-5 months) groups, were procured from Panacea
Biotec Limited, Lalru (India). They were kept in polypropylene cages and housed in standard laboratory conditions at $25 \pm 2^{\circ} \mathrm{C}$ with alternate light and dark cycle of 12 hours each. All the experimental animals were allowed a free access to standard rat pellet diet and water. Prior to start the experimental work, the rats were acclimatized to experimental laboratory conditions for one week. The study protocol was duly approved by the Institutional Animal Ethical Committee [CTIPS/2014/IV/0020(PCL-D)]. The care and experimental handling of animals were taken as per the guidelines of CPCSEA (Committee for the Purpose of Control and Supervision of Experiments on Animals), Ministry of Environment \& Forests, Government of India, New Delhi.

\section{Preparation of extract}

The hydroethanolic extract of $P$. perlata, was prepared using the extraction procedure as previously carried out in our laboratory (Goyal et al., 2017). Briefly, $100 \mathrm{~g}$ coarsely powdered drug was mixed with $2500 \mathrm{ml} 60 \%$ ethanol, in a stoppered glass container and kept at $45^{\circ} \mathrm{C}$ for five days with occasional shaking. The contents were filtered through Whatman No. 1 filter paper and the filtrate obtained was concentrated under vacuum using a rotary evaporator. The concentrated contents were dried to constant weight at $45^{\circ} \mathrm{C}$ in a hot air oven and labeled as PPE i.e. $P$. perlata extract. PPE was stored in a sterile glass container and kept in a refrigerator.

\section{Animal model for inducing hyperoxaluria}

Ethylene glycol (EG) and ammonium chloride (AC) induced hyperoxaluria in rat model was employed to assess the antiurolithiatic potential. The rats were treated with $0.75 \% \mathrm{v} / \mathrm{v}$ EG and $1 \% \mathrm{w} / \mathrm{v} \mathrm{AC}$ in drinking water ad libitum for first three days to accelerate lithiasis followed by only $0.75 \% \mathrm{v} / \mathrm{v}$ EG in drinking water for the remaining period of six week study (Goyal et al., 2017; Prabhu et al., 2016).

\section{Experimental design}

Thirty-six Wistar rats were randomly divided into six groups, each containing six animals. The different groups were treated and designated as follows:

Group I (Normal control): The rats were maintained on a standard pellet diet and water ad libitum for six weeks. The vehicle $(10 \% \mathrm{v} / \mathrm{v}$ Tween 80 solution) was orally administered once daily.

Group II (Urolithiatic control): The rats were allowed a free access to EG + AC containing drinking water for 1-3 days followed by only EG containing water for the remaining period of study. After two weeks of treatment, the vehicle was orally administered once daily for remaining four week period. The rats were allowed a free access to standard rat diet through the whole study tenure.

Group III (Standard groups): For the first two weeks, the rats were treated same as in the urolithiatic control group II. After two weeks of the treatment period, the vehicle, $10 \% \mathrm{v} / \mathrm{v}$ Tween 80 solution was replaced with standard drug CST $(500 \mathrm{mg} / \mathrm{kg}$; p.o.) for remaining periods of four weeks.

Group IV to VI (Test groups): For first two weeks, the rats were treated same as in the urolithiatic control group II. After two weeks of the treatment period, the rats of different groups were administered with PPE (100, 300 and $500 \mathrm{mg} / \mathrm{kg}$; p.o. respectively) instead of vehicle for next four weeks. 
The extract was emulsified in $10 \% \mathrm{v} / \mathrm{v}$ Tween 80 . After two weeks treatment, the rats of group II-VI were individually kept in metabolic cages for $24 \mathrm{~h}$ to collect the urine samples. The urine samples were microscopically examined for the presence of $\mathrm{CaOx}$ crystals and the animals showing the presence of urinary crystals were selected for further study.

\section{Biochemical analysis}

\section{Collection and analysis of urine}

After six week treatment period, the animals were individually kept in metabolic cages for 24 hours and urine samples were collected. After measuring the urine volume and $\mathrm{pH}$, the collected urine volumes were divided into two parts. One part was acidified with 1-2 drops of $1 \mathrm{~N}$ Hydrochloric acid. In order to remove the debris, both the acidified and non-acidified urine samples were centrifuged at $1500 \mathrm{rpm}$ for 10 minutes (Goyal et al., 2017). The calcium, magnesium and phosphorus contents were estimated in acidified urine sample using standard reagent kits (Erba Diagnostics Mannheim, GmbH, Germany). The non-acidified urine sample was subjected to estimate the oxalate contents by Hodgkinson's method (Hodgkinson, 1970). The urinary creatinine, urea, uric acid, and total protein contents in the non-acidified sample were estimated using commercially available standard reagent kits (Erba Diagnostics Mannheim, GmbH, Germany).

\section{Collection and analysis of serum}

After collecting the urine, the blood samples were collected from retro-orbital sinus of each animal and serum was separated by centrifugation at $2000 \mathrm{rpm}$ for 10 minutes. The serum was quantitatively analyzed for creatinine, uric acid, urea nitrogen, magnesium, calcium, phosphorus, and lactate dehydrogenase (LDH) using spectrophotometric methods by employing commercially available standard reagent kits (Erba Diagnostics Mannheim, GmbH, Germany).

\section{Kidney tissue homogenate analysis}

After collecting the blood samples, the animals were sacrificed by cervical dislocation. The abdomen was cut opened and both the kidneys were carefully isolated. The isolated kidneys were cleaned of the extraneous tissues in ice-cold saline and weighed. One kidney was preserved in $10 \%$ buffered neutral formalin for the purpose of histological studies. The other kidney was sliced into two equal halves. One-half was dried at $80^{\circ} \mathrm{C}$ in a hot air oven. A sample of $100 \mathrm{mg}$ of the dried kidney was boiled in 10 $\mathrm{ml}$ of $1.0 \mathrm{~N}$ hydrochloric acid for about 30 minutes and homogenized. The homogenate was then centrifuged at $2000 \mathrm{~g}$ for 10 minutes and the supernatant was separated (Chow et al., 1975; Gadge and Jalalpure, 2012; Goyal et al., 2017). The supernatant was used for estimating the calcium and phosphorus contents with commercially available kits (Erba Diagnostics Mannheim, $\mathrm{GmbH}$, Germany). The oxalate contents were measured by Hodgkinson's method (Hodgkinson, 1970). The other half of kidney was minced and a $10 \%$ homogenate was prepared in tris- $\mathrm{HCl}$ buffer $\mathrm{pH}$ 7.0. The homogenate was then subjected to LDH estimation by employing commercially available standard reagent kits for spectrophotometric methods (Dodoala et al., 2010; Goyal et al., 2017; Soundararajan et al., 2006).

\section{Histopathological studies}

The kidneys, fixed in 10\% buffered formalin ( $\mathrm{pH} 7.0$ ) solution, were dehydrated with ascending grades of ethanol and embedded in paraffin. The 4-6 $\mu \mathrm{m}$ thick sections of paraffin kidney were cut, mounted on slides, deparaffinised and rehydrated with descending grades of ethanol. After staining with hematoxylin and eosin, the kidney sections were examined (at 400x), under a light microscope equipped with a digital camera, for the presence of crystals of $\mathrm{CaOx}$ and various renal pathological changes like tubular necrosis, glomerular and tubular architecture etc. (Atmani et al., 2009; Goyal et al., 2017; Pareta et al., 2011).

\section{Data analysis}

All the values were expressed as mean \pm SEM (standard error mean). The data were analyzed by employing One-way ANOVA followed by Tukey's multiple comparison tests using GraphPad Prism 5.0 software. The values of $\mathrm{p}<0.05$ were considered as significant.

\section{RESULTS AND DISCUSSION}

$\mathrm{EG}+\mathrm{AC}$ induced hyperoxaluria in rats is the highly reliable and widely used experimental model for preclinical evaluation of antiurolithiatic agents. The oxalate metabolism in rats is almost similar to that of human beings, so the rats were preferred in this study (Goyal et al., 2017; Pawar and Vyawahare, 2015). EG, when administered to rats in drinking water, is readily absorbed, and increase the substrate availability for oxalate synthesizing enzymes like glycolic acid oxidase (GAO) in liver and $\mathrm{LDH}$ in liver and kidney. This leads to hyperoxaluria which is one of the major risk factors for $\mathrm{CaOx}$ urolithiasis (Liao and Richardson, 1972; Soundararjan et al., 2006). Administration of AC along with EG acidify the urine and facilitate crystallization of oxalate (Fan et al., 1999). The oxalates, as poorly soluble, readily precipitate as $\mathrm{CaOx}$ and damage the epithelial lining of renal tubules that leads to adhesion and retention of crystals (Scheid et al., 2004; Thamilselvan et al., 2003).

\section{Effects of PPE on urine output and pH}

In the present study, administration of $\mathrm{EG}+\mathrm{AC}$ significantly reduced the urine output and acidify the urine in lithiatic group when compared with normal control as shown in Table 1. The reduced urine output supersaturates the urine and favors the crystallization of oxalates. The acidification of urine also facilitates the stone formation (Vermeulen et al., 1951). PPE significantly enhanced the urine volume and $\mathrm{pH}$ as represented in Table 1. The enhanced urine volume hampered the crystal formation as well as facilitated the flushing out of crystals. The raised $\mathrm{pH}$ also hindered the stone formation. The best effects were seen in the PPE $500 \mathrm{mg} / \mathrm{kg}$ treated group.

\section{Effects of PPE on oxalate and LDH levels}

A significant increase in the oxalate levels of urine and kidney tissue homogenates was observed in $\mathrm{EG}+\mathrm{AC}$ treated rats. The hyperoxaluria is considered as the major risk factor of $\mathrm{CaOx}$ urolithiasis (Khan, 2004). LDH is an oxalate synthesizing enzyme present in liver and kidney. The enhanced LDH levels in EG + $\mathrm{AC}$ treated rats also indicated the prominent hyperoxaluric con- 
ditions. PPE significantly prevented the hyperoxaluric conditions, in a dose-dependent manner, by decreasing the elevated oxalate and LDH levels in the urine and kidney tissue homogenates as depicted in Table 1.

Table 1: Effects of PPE on urine output, urine $\mathrm{pH}$, oxalate, and LDH levels in hyperoxaluric rats.

\begin{tabular}{|c|c|c|c|c|c|c|}
\hline Parameters & Normal Control & Lithiatic Control $^{\mathrm{s}}$ & CST $500 \mathrm{mg} / \mathrm{kg}^{\#}$ & PPE $100 \mathrm{mg} / \mathrm{kg}^{\#}$ & PPE $300 \mathrm{mg} / \mathrm{kg}^{\#}$ & PPE $500 \mathrm{mg} / \mathrm{kg}^{\#}$ \\
\hline Ur. Vol. (ml/24 hrs) & $19.70 \pm 0.71$ & $10.62 \pm 0.42^{* * * *}$ & $21.77 \pm 0.66^{* * * *}$ & $11.58 \pm 0.60^{\mathrm{ns}}$ & $12.53 \pm 0.63^{\mathrm{ns}}$ & $15.10 \pm 0.43^{* * * *}$ \\
\hline Ur. $\mathrm{pH}$ & $7.77 \pm 0.27$ & $6.25 \pm 0.12^{* * * *}$ & $8.17 \pm 0.19^{* * * *}$ & $7.95 \pm 0.26^{* * *}$ & $7.50 \pm 0.18^{* * *}$ & $8.02 \pm 0.12^{* * * *}$ \\
\hline Ur. Ox (mg/dl) & $0.34 \pm 0.05$ & $4.82 \pm 0.42^{* * *}$ & $0.98 \pm 0.15^{* * *}$ & $3.98 \pm 0.13^{\mathrm{ns}}$ & $3.22 \pm 0.20^{* * * *}$ & $1.98 \pm 0.12^{* * * *}$ \\
\hline KH. Ox (mg/g) & $2.80 \pm 0.19$ & $7.34 \pm 0.57^{* * * *}$ & $2.74 \pm 0.18^{* * * *}$ & $5.82 \pm 0.42^{\mathrm{ns}}$ & $4.56 \pm 0.38^{* * * *}$ & $4.08 \pm 0.26^{* * * *}$ \\
\hline Sr. LDH (U/I) & $848.92 \pm 108.20$ & $2396.34 \pm 217.50^{* * * *}$ & $1023.25 \pm 65.32^{* * * *}$ & $1982.84 \pm 135.18^{\mathrm{ns}}$ & $1622.14 \pm 118.41^{* *}$ & $1295.56 \pm 89.36^{* * *}$ \\
\hline KH. LDH (U/g) & $1.98 \pm 0.26$ & $5.04 \pm 0.44^{* * *}$ & $1.92 \pm 0.09^{* * * *}$ & $4.07 \pm 0.29^{\mathrm{ns}}$ & $3.33 \pm 0.21^{* *}$ & $2.98 \pm 0.22^{* * * *}$ \\
\hline
\end{tabular}

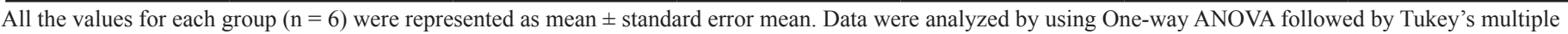
comparison test.

${ }^{* * * *} \mathrm{p}<0.001 ;{ }^{* *} \mathrm{p}<0.01 ;{ }^{*} \mathrm{p}<0.05 ;{ }^{\mathrm{ns}}$ not significant; ${ }^{\$}$ compared with normal control; ${ }^{*}$ compared with lithiatic control

Ur. - Urine, Vol. - Volume, KH. - Kidney Tissue Homogenate, Ox - Oxalate, Sr. - Serum, LDH - Lactate dehydrogenase

\section{Effects of PPE on renal functions assessing parameters}

Once the urinary crystals of $\mathrm{CaOx}$ produced, they agglomerate and tend to retain in renal tubules. They tend to damage the renal tissues, decrease the glomerular filtration, obstruct the urine outflow and facilitate the accumulation of various waste products especially nitrogenous substances in blood (Karadi et al., 2006; Pareeta et al., 2011; Rathod et al., 2012).

In the present study, administration of EG + AC significantly altered the renal functions in lithiatic rats and indicated by increased serum concentration of creatinine, uric acid, BUN, and decreased creatinine clearance. The increased BUN, serum creatinine, and reduced creatinine clearance are the markers of tubular and glomerular damage in the kidney (Karadi et al., 2006). PPE significantly decreased the serum concentration of creatinine in a dose-dependent manner as shown in Table 2. It improved the creatinine clearance and showed significant effects at $500 \mathrm{mg} /$ $\mathrm{kg}$. PPE $(100,300$, and $500 \mathrm{mg} / \mathrm{kg})$ significantly decreased the BUN levels in a dose-dependent manner. The elevated uric acid is reported to promote the growth of $\mathrm{CaOx}$ crystals (Grover et al., 1990). PPE (500 mg/kg) significantly decreased the serum concentration of uric acid and altered the growth of crystals. EG $+\mathrm{AC}$ treatment increased the urinary protein levels and caused proteinuria. The proteinuria reflected the dysfunctions of proximal convoluted tubules (Resnick et al., 1979). PPP significantly ( $\mathrm{p}<$ 0.001 ) reduced the urine levels of proteins and improved tubular functions. The effects of PPE $(500 \mathrm{mg} / \mathrm{kg})$ on serum creatinine, creatinine clearance, BUN, and urinary protein levels were found to be comparable with that of reference drug CST.

Table 2: Effects of PPE on renal function assessing parameters in hyperoxaluric rats.

\begin{tabular}{|c|c|c|c|c|c|c|}
\hline Parameters & Normal Control & Lithiatic Control $^{\$}$ & CST $500 \mathrm{mg} / \mathrm{kg}^{\#}$ & PPE $100 \mathrm{mg} / \mathrm{kg}^{\#}$ & PPE 300 mg/kg ${ }^{\#}$ & PPE $500 \mathrm{mg} / \mathrm{kg}^{\#}$ \\
\hline Sr. Cre. (mg/dl) & $0.46 \pm 0.08$ & $1.56 \pm 0.11^{* * * *}$ & $0.57 \pm 0.03^{* * * *}$ & $0.99 \pm 0.04^{* * *}$ & $0.75 \pm 0.02^{* * *}$ & $0.58 \pm 0.04^{* * * *}$ \\
\hline Cre. Clr (ml/min.) & $0.59 \pm 0.02$ & $0.42 \pm 0.01^{*}$ & $0.63 \pm 0.02^{* * *}$ & $0.54 \pm 0.03^{\mathrm{ns}}$ & $0.56 \pm 0.04^{\mathrm{ns}}$ & $0.65 \pm 0.04^{* * * *}$ \\
\hline BUN (mg/dl) & $19.66 \pm 0.87$ & $48.86 \pm 3.77^{* * *}$ & $20.99 \pm 0.75^{* * *}$ & $34.91 \pm 1.87^{* * * *}$ & $25.62 \pm 1.17^{* * *}$ & $22.08 \pm 0.99^{* * *}$ \\
\hline Sr. UAC (mg/dl) & $0.39 \pm 0.03$ & $2.04 \pm 0.27^{* * *}$ & $0.40 \pm 0.05^{* * *}$ & $1.322 \pm 0.369^{\mathrm{ns}}$ & $1.317 \pm 0.255^{\mathrm{ns}}$ & $0.703 \pm 0.137^{* * *}$ \\
\hline Ur. Pro. (g/dl) & $0.13 \pm 0.02$ & $0.79 \pm 0.04^{* * *}$ & $0.20 \pm 0.03^{* * *}$ & $0.37 \pm 0.02^{* * * *}$ & $0.35 \pm 0.02^{* * *}$ & $0.24 \pm 0.02^{* * *}$ \\
\hline
\end{tabular}

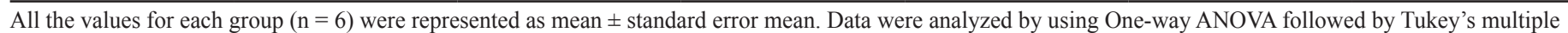
comparison test.

${ }^{* * *} \mathrm{p}<0.001 ;{ }^{* *} \mathrm{p}<0.01 ;{ }^{*} \mathrm{p}<0.05 ;{ }^{\mathrm{ns}}$ not significant; ${ }^{\$}$ compared with normal control; ${ }^{\#}$ compared with lithiatic control Sr. - Serum, Cre - Creatinine, Clr. - Clearance, BUN - Blood Urea Nitrogen, UAC - Uric acid, Ur. - Urine, Pro. - Protein

\section{Effects of PPE on other stone promoting and inhibiting factors}

Formation of urinary stone is considered to be affected by various stone promoting and inhibiting factors. The calcium and phosphorus are considered as the stone promoting inorganic factors while the magnesium is stone inhibiting (Basavaraj et $a l ., 2007)$. In the present study, EG + AC treatment significantly elevated the calcium and phosphorus level in urine, serum, and kidney tissue homogenates of hyperoxaluric rats as shown in Table 3 . It also significantly decreased the urinary and serum concentration of magnesium. Hypercalciuria favors the nucleation and precipitation of $\mathrm{CaOx}$ in urine that leads to crystal growth
(Lemann et al., 1991). Hypercalcemia was also reported in urolithiasis patients (Bhale et al., 2013). Increased urinary phosphorus level has also been reported in hyperoxaluric rats (Subha and Varalakshmi, 1993). In hyperoxaluric condition, multiple cations tend to complex with oxalates to form urinary salts of oxalate. The magnesium salts are soluble while the calcium salts are insoluble and facilitate the precipitation of calculi of $\mathrm{CaOx}$ (Marshall and Robertson, 1976). PPE significantly reversed the urine, serum and kidney tissue homogenate levels of calcium towards normal range in a dose-dependent manner as shown in Table 3. The significant effects of PPE on magnesium levels in urine were seen at 300 and $500 \mathrm{mg} / \mathrm{kg}$, while in serum at only $500 \mathrm{mg} / \mathrm{kg}$. It significantly 
reduced the elevated serum phosphorus toward normal but did not produce any significant effect on urine and kidney tissue homogenate levels. The remarkable effecsts of PPE on these stone pro- moting/inhibiting factors were observed at $500 \mathrm{mg} / \mathrm{kg}$, and found to be comparable with that of reference drug CST.

Table 3: Effects of PPE on inorganic stone promoting/inhibiting factors in hyperoxaluric rats.

\begin{tabular}{|c|c|c|c|c|c|c|}
\hline Parameters & Normal Control & Lithiatic Control $^{\$}$ & CST $500 \mathrm{mg} / \mathrm{kg}^{\#}$ & PPE $100 \mathrm{mg} / \mathrm{kg}^{\#}$ & PPE $300 \mathrm{mg} / \mathrm{kg}^{\#}$ & PPE $500 \mathrm{mg} / \mathrm{kg}^{\sharp}$ \\
\hline Ur. Ca (mg/dl) & $1.19 \pm 0.17$ & $4.86 \pm 0.42^{* * * *}$ & $0.91 \pm 0.08^{* * * *}$ & $3.13 \pm 0.22^{* * *}$ & $2.13 \pm 0.10^{* * * *}$ & $1.32 \pm 0.23^{* * *}$ \\
\hline Sr. Ca (mg/dl) & $8.78 \pm 0.38$ & $14.09 \pm 0.88^{* * *}$ & $7.64 \pm 0.39^{* * *}$ & $9.10 \pm 0.41^{* * * *}$ & $8.30 \pm 0.35^{* * *}$ & $7.53 \pm 0.53^{* * * *}$ \\
\hline KH. Ca (mg/g) & $4.34 \pm 0.37$ & $11.70 \pm 0.89^{* * * *}$ & $5.02 \pm 0.26^{* * * *}$ & $8.85 \pm 0.54^{*}$ & $7.22 \pm 0.35^{* * *}$ & $6.96 \pm 0.32^{* * * *}$ \\
\hline Ur. Ma (mg/dl) & $4.70 \pm 0.10$ & $3.62 \pm 0.15^{* * *}$ & $4.91 \pm 0.11^{* * *}$ & $4.13 \pm 0.11^{\mathrm{ns}}$ & $4.33 \pm 0.18^{*}$ & $4.77 \pm 0.20^{* * * *}$ \\
\hline Sr. Mg (mg/dl) & $2.51 \pm 0.23$ & $1.38 \pm 0.06^{*}$ & $3.18 \pm 0.27^{* * * *}$ & $2.01 \pm 0.13^{\mathrm{ns}}$ & $2.05 \pm 0.31^{\mathrm{ns}}$ & $2.53 \pm 0.27^{*}$ \\
\hline Ur. P (mg/dl) & $1.37 \pm 0.10$ & $3.92 \pm 0.20^{* * *}$ & $1.10 \pm 0.07^{* * * *}$ & $3.69 \pm 0.15^{\text {ns }}$ & $3.28 \pm 0.13^{\mathrm{ns}}$ & $3.19 \pm 0.30^{\mathrm{ns}}$ \\
\hline Sr. P (mg/dl) & $4.71 \pm 0.27$ & $7.44 \pm 0.38^{* * *}$ & $4.31 \pm 0.19^{* * * *}$ & $5.64 \pm 0.29^{* * * *}$ & $5.53 \pm 0.21^{* * *}$ & $4.11 \pm 0.40^{* * * *}$ \\
\hline KH. P (mg/g) & $1.49 \pm 0.18$ & $4.63 \pm 0.52^{* * *}$ & $2.47 \pm 0.14^{* * *}$ & $4.28 \pm 0.36^{\mathrm{ns}}$ & $4.44 \pm 0.28^{\mathrm{ns}}$ & $4.02 \pm 0.34^{\mathrm{ns}}$ \\
\hline
\end{tabular}

All the values for each group $(n=6)$ were represented as mean \pm standard error mean. Data were analyzed by using One-way ANOVA followed by Tukey's multiple comparison test.

${ }^{* * *} \mathrm{p}<0.001 ;{ }^{*} \mathrm{p}<0.05 ;{ }^{\text {ns }}$ not significant; ${ }^{\$}$ compared with normal control; ${ }^{*}$ compared with lithiatic control

Ur. - Urine, Sr. - Serum, KH. - Kidney Tissue Homogenate, Ca - Calcium, Mg - Magnesium, P - Phosphorus
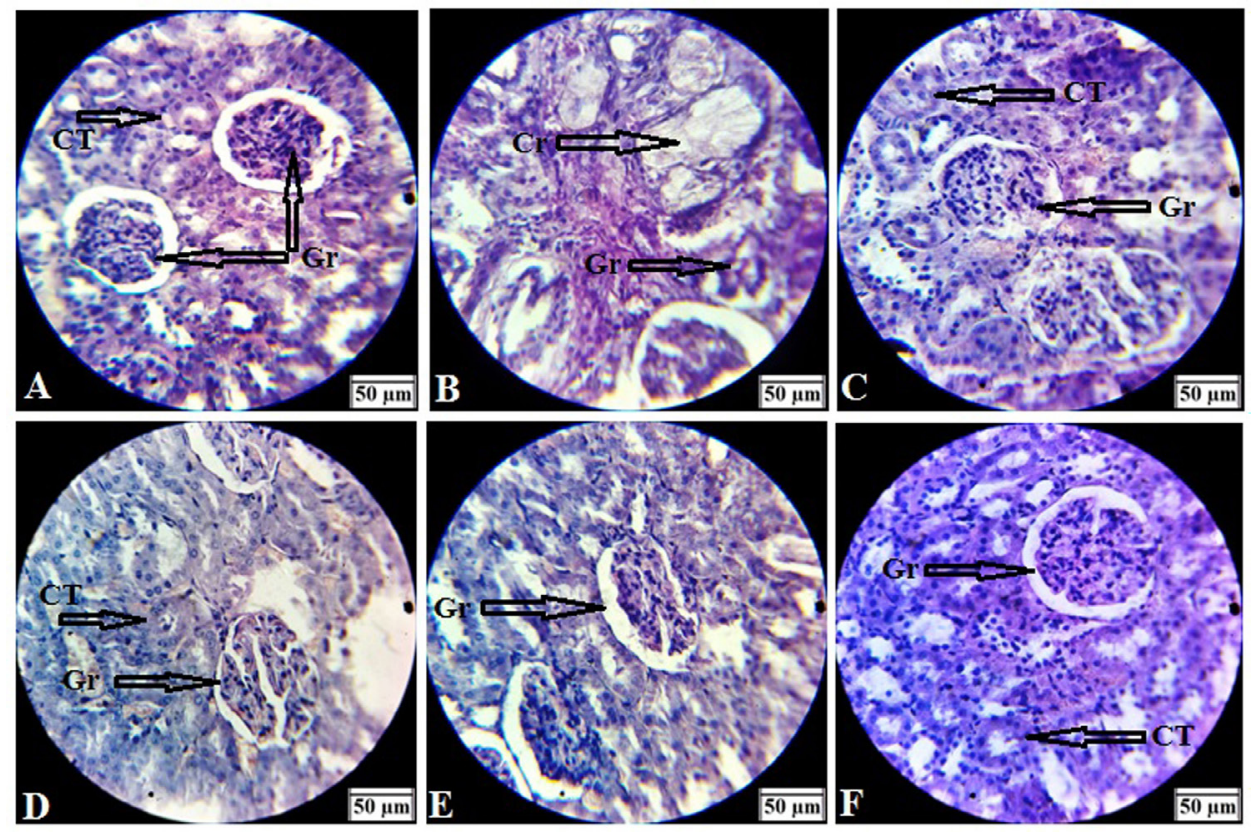

Fig. 1: Histological images (400 x) of normal, hyperoxaluric and treated rat kidney. (A) Normal control treated with vehicle, (B) Urolithiatic (hyperoxaluric) control treated with EG + AC, (C) Standard group: hyperoxaluric rats treated with CST. (D-E) Test groups: hyperoxaluric rats treated with 100, 300, and 500 mg/kg PPE respectively.

$\mathrm{Cr}-\mathrm{CaOx}$ crystals; $\mathrm{CT}$ - Convoluted tubules; $\mathrm{Gr}$ - Glomerulus

\section{Histopathological study}

The microscopic examinations of histopathological slides shown in Figure 1 supported the results of the biochemical analysis. The rats in the control group (Figure $1 \mathrm{~A})$ showed a normal renal architecture without any crystal deposition. The slides of lithiatic group showed the presence of large sized crystals of $\mathrm{CaOx}$, glomerular atrophy, and altered renal architecture (Figure 1B). Crystal deposition is usually associated with cellular injury and caused a variety of changes in renal architecture that facilitate crystal retention. The interactions between injured tubular epithelial cells and oxalate crystals are considered to have a significant role in the development of urinary stones (Aggarwal et al., 2010; Bijarnia et al., 2008; Grover et al., 1990; Khan, 2004; Khan et al., 2000). PPE (100, 300 and $500 \mathrm{mg} / \mathrm{kg}$ ), when compared with urolithiatic group, significantly restored the normal renal architecture as shown in Figure 1 D, E, and F respectively. No $\mathrm{CaOx}$ crystals were observed and the normal cellular organizations of proximal and distilled convoluted tubules were restored. The normal glomerular sizes and renal architectures were recovered. The 
effects of PPE were found to be comparable with that of the reference drug as shown in Figure $1 \mathrm{C}$.

\section{CONCLUSION}

The present study concluded that $P$. perlata extract exhibited significant antiurolithiatic potentials against $\mathrm{CaOx}$ calculi in experimental rats. It significantly restored the normal renal architecture and improved the renal functions by restoring the $\mathrm{EG}+\mathrm{AC}$ mediated biochemical changes in urine, serum and kidney tissue homogenate parameters of experimental rats towards normal.

\section{CONFLICT OF INTEREST}

The authors have declared no conflict of interests.

\section{ACKNOWLEDGEMENT}

The authors are thankful to I.K.G. Punjab Technical University, Jalandhar (Punjab), India for providing a platform to carry out this research work. The authors are also thankful to Aimil Pharmaceutical India Limited, New Delhi for providing gift samples of authenticated $P$. perlata.

\section{REFERENCES}

Abdullah ST, Hamid H, Ali M, Ansari SH, Alam M.S. Two new terpenes from the lichen Parmelia perlata. Indian J Chem 2007; 46B (1): $173-6$

Aggarwal A, Tandon S, Singla SK, Tandon C. Diminution of oxalate induced renal tubular epithelial cell injury and inhibition of calcium oxalate crystallization in-vitro by aqueous extract of Tribulus terrestris. Int Braz J Urol, 2010; 36(4): 480-489.

Aggarwal KP, Narula S, Kakkar M, Tandon C. Nephrolithiasis: molecular mechanism of renal stone formation and the critical role played by modulators. Biomed Res Int, 2013; doi: 10.1155/2013/292953.

Atmani F, Sadki C, Aziz M, Mimouni M, Hacht B. Cynodon dactylon extract as a preventive and curative agent in experimentally induced nephrolithiasis. Urol Res, 2009; 37:75-82.

Basavaraj DR, Biyani CS, Browning AJ, Cartledge JJ. The role of urinary kidney stone inhibitors and promoters in the pathogenesis of calcium containing renal stones. Eau-Ebu Update Series, 2007; 5:126136

Bhale DV, Hivre MD, Mahat RK, Bujurge AA. Study of serum calcium, phosphorus and uric acid levels in patients of urinary calculi. Int $\mathrm{J}$ Recent Trends Sci Tech, 2013; 9(2):189-190.

Bijarnia RK, Kaur T, Aggarwal K, Singla SK, Tandon C. Modulatory effects of $\mathrm{N}$-acetylcysteine on hyperoxaluric manifestations in rat kidney. Food Chem Toxicol, 2008; 46:2274-2278.

Chow FC, Dysart MI, Hamar DW, Udall RH. Control of oxalate urolithiasis by DL-alanine. Invest Urol, 1975; 13:113-116.

Dodoala S, Diviti R, Koganti B, Prasad KVSRG. Effect of EtOH extract of Phyla nodiflora (Linn) Greene against calculi producing diet-induced urolithiasis. Indian J Nat Pdt Res, 2010; 1(3):314-321.

Fan J, Michael AG, Chandhoke PS. Impact of ammonium chloride administration on a rat ethylene glycol urolithiasis model. Scanning Microsc, 1999; 13:299-306.

Gadge NB, Jalalpure SS. Curative treatment with extracts of Bombax ceiba fruit reduces risk of calcium oxalate urolithiasis in rats. Pharm Biol, 2012; 50(3):310-317.

Goyal PK, Verma SK, Sharma AK. Antilithiatic potential of Vernonia cinerea against calcium oxalate calculi in experimental rats. J Phytopharmacol, 2017; 6(2):149-155.

Goyal PK, Verma SK, Sharma AK. Pharmacological and phytochemical aspects of lichen Parmelia perlata: A review. Int J Res Ayu Pharm, 2016; 7(suppl 1):102-107. DOI: 10.7897/2277-4343.07138.
Grover PK, Ryall RL, Marshall VR. Effect of urate on calcium oxalate crystallization in human urine: Evidence for a promontory role of hyperuricosuria in urolithiasis. Clin Sci, 1990; 79(1):9-15.

Hodgkinson A. Determination of oxalic acid in biological material. Clin Chem, 1970; 16:547-557.

Jothi G, Brindha P. Antidiabetic and antihyperlipidemic effect of Parmelia perlata Ach. in alloxan induced diabetic rats. Int J Pharm Pharm Sci, 2013; 6(1): 43-46.

Karadi RV, Gadge NB, Alagawadi KR, Savadi RV. Effect of Moringa oleifera Lam. root-wood on ethylene glycol induced urolithiasis in rats. J Ethnopharmacol, 2006; 105:306-311.

Khan SR, Thamilselvan S. Nephrolithiasis, a consequence of renal epithelial cell exposure to oxalate and calcium oxalate crystals. Mol Urol, 2000; 4:305-311.

Khan SR. Animal models of kidney stone formation: An analysis. World J Urol, 1997; 15:236-243

Khan SR. Role of renal epithelial cells in the initiation of calcium oxalate stones. Nephron Exp Nephrol, 2004; 98(2):e55-60.

Khare CP. 2007. Indian medicinal plants An Illustrated Dictionary. Berlin/Heidelberg, New York: Springer.

Lakshmi V, Ameta K, Mishra V, Srivastava A, Agarwal SK, Palit G, Mahdi AA. Gastroprotective effect of ethanolic extract of Parmelia perlata in rats. J Phytopharmacol, 2013; 2(6): 19-25.

Lemann J, Worcester, EM, Gray RW. Hypercalciuria and stones. Am J Kidney Disease, 1991; 17:386-391.

Li X, Wang W, Su Y, Yue Z, Bao J. Inhibitory effect of an aqueous extract of Radix Paeoniae Alba on calcium oxalate nephrolithiasis ina rat model. Renal Failure, 2017; 39(1) 120-129. DOI: 10.1080/0886022X.2016.1254658.

Liao LL, Richardson KE. The metabolism of oxalate precursors in isolated perfused rat liver. Arch Biochem Biophys, 1972; 153(2):438-448.

Marshall RW, Robertson WG. Nanograms for the estimation of the saturation of urine with calcium oxalate, calcium phosphate, magnesium ammonium phosphate, uric acid, sodium acid urate. Clin Chim Acta, 1976; 72(2):253-260

Moe OW. Kidney stones: Pathophysiology and medical management. Lancet, 2006; 367:333-344.

Nadkarni KM. India Materia Medica, third enlarges and revised ed. India: Bombay Popular Prakashan; 2002.

Pareta SK, Patra KC, Mazumder PM and Sasmal D. Aqueous extract of Boerhaavia diffusa root ameliorates ethylene glycol-induced hyperoxaluric oxidative stress and renal injury in rat kidney. Pharm Biol, 2011; 49(12):1224-1233.

Pawar AT, Vyawahare NS. Protective effect of standardized extract of Biophytum sensitivum against calcium oxalate urolithiasis in rats Bull Facul Pharm Cairo Uni, 2015; 53(2):161-172.

Prabhu VV, Sathyamurthy D, Ramasamy A, Das S, Anuradha M, Pachiappan S. Evaluation of protective effects of diosmin (a citrus flavonoid) in chemical-induced urolithiasis in experimental rats. Pharm Biol, 2016; 54:1-9

Rahman H, Vijaya B, Ghosh S, Pant G, Sibi G. In vitro studies on antioxidant, hypolipidemic and cytotoxic potential of Parmelia perlata. Am J Life Sci, 2014; 2(6): 7-10.

Rathod NR, Biswas D, Chitme HR, Ratna S, Muchandi IS, Chandra R. Anti-urolithiatic effects of Punica granatum in male rats. J Ethnopharmacol, 2012; 140(2):234-238.

Resnick MI, Boyce WH. Low molecular weight urinary proteins and renal lithiasis. Invest Urol, 1979; 16(4):270-273.

Scheid CR, Cao LC, Honeyman T, Jonassen JA. How elevated oxalate can promote kidney stone disease: changes at the surface and in the cytosol of renal cells that promote crystal adherence and growth. Front Biosci, 2004; 9:797-808.

Shailajan S, Joshi M, Tiwari B. Hepatoprotective activity of Parmelia perlata (Huds.) Ach. against $\mathrm{CCl}_{4}$ induced liver toxicity in Albino Wistar rats. J App Pharm Sci, 2014; 4 (02): 70-74.

Sharma AK, Sharma KK, Sharma MC, Dobhal MP. Two diben- 
zofurans identified as heterocyclic natural compounds from lichen Parmelia perlata. J Pharmacog Phytochem 2014; 2(5): 95-97.

Sharma AK, Sharma MC, Dobhal MP. Phytochemical investigation of therapeutic important lichen: Parmelia perlata. J Nat Prod Plant Resour 2012; 2(1): 101-106.

Soundararajan P, Mahesh R, Ramesh T, BegumVZ. Effect of Aerva lanata on calcium oxalate urolithiasis in rats. Indian J Exp Biol, 2006; 44:981-986.

Subha K, Varalakshmi P. Alterations in some risk factors and urinary enzymes in urolithiatic rats treated with sodium pentasan polysulfate. Biochem. Mol Biol Int, 1993; 29(2):271-280.

Thamilselvan S, Khan SR, Menon M. Oxalate and calcium oxalate mediated free radical toxicity in renal epithelial cells: effect of antioxidants. Urol Res, 2003; 31:3-9.

The Ayurvedic Pharmacopoeia of India. 2001. first ed., Part 1, Vol.- III, Govt. of India, Ministry of Health and Family Welfare, Department of Indian System of Medicine and Homeopathy, Delhi: published by the controller of publications.
Thippeswamy B, Sushma NR, Naveenkumar KJ. Evaluation of antimicrobial property of lichen - Parmelia perlata. Afr J Pharm Pharmacol, 2013; 7(20): 1242-50.

Vermeulen CW, Ragins HD, Goetz R, Grove WJ. Experimental urolithiasis III. Prevention and dissolution of calculi by alteration of urinary pH. J Urol, 1951; 66:24-28.

Vidyalakshmi A, Kruthika K. Antibacterial activity of Parmelia perlata. Asian Pacific J Tropical Biomed, 2012; S892-S894.

\section{How to cite this article:}

Goyal PK, Verma SK, Sharma AK. Evaluation of antiurolithiatic effects of Parmelia perlata against calcium oxalate calculi in hyperoxaluric rats. J App Pharm Sci, 2018; 8 (01): 129-135. 